the general problems of genetical history and differentiation in the tuberous species of Solanum. The valuable research material that has been assembled will thus continue to be used to the ultimate ad. vantage of the potato industry. The Potato Genetics Station is under the direction of Dr. K. S. Dodds.

\section{Acustica : A New International Journal}

THE first two numbers have recently appeared of Acustica (Zurich: Hirzel-Verlag, 1951; 36 Swiss francs a year), a new international journal sponsored by the Acoustics Group of the Physical Society of London. There have been previous attempts to start national acoustical journals in both France and Germany, but neither of these survived the Second World War. In recent years hopes have been expressed for a revival of these and for the setting-up of a journal in English on the eastern side of the Atlantic, sponsored by the respective groups of scientific workers and technicians interested in acoustics. Eventually it was decided to combine these efforts and to found a journal which should publish articles received in English, French or German of any origin but particularly those coming from European countries and from countries associated therewith, such as the British Commonwealth. Dr. C. W. Kosten, of Delft, was appointed editor-in-chief, and Dr. E. G. Richardson, of King's College, Newcastle upon Tyne, is the editor for papers submitted in the English language. Acustica will appear six times a year and will publish from time to time additional one-language supple. ments under subvention by one or other of the national groups. (One such supplement, in German, has already appeared.) For the main joumal, up to the present more papers have been received in English than in any other language, but those printed in the first two issues include some in all three languages. Between them they cover the subjects of building acoustics, subjective sound, musical acoustics, ultrasonics, loud-speakers and the history of sound. It is indeed the aim of the editors that fundamental, and not cnly technological, aspects of sound shall be well represented in the journal.

\section{Study of the Arthropod Mandible}

IT is generally accepted that the mandibles of an arthropod have evolved from a pair of limbs in a primitive ancestral form, though precisely which part or parts of the limb is involved is still a subject of discussion. The typical, primitive arthropod limb consisted of a basal coxopodite or coxa and a distal segmented telopodite. The coxa was articulated dorsally on the tergum and ventrally on the sternum, and the limb was moved antero-posteriorly probably by a pair of dorsal muscles originating from the tergum and a pair of ventral muscles originating from the sternum or an endophragmal projection therefrom. These muscles may be termed the dorsal promotor and remotor and the ventral promotor and remotor, respectively. A change in the position of the points of articulation or in the places of origin of the muscles or both would, of course, bring about a change in the direction of movement of the limb. Starting with these quite reasonable assumptions, R. E. Snodgrass has carried out a most interesting series of "Comparative Studies on the Jaws of Mandibulate Arthropods" (Smithsonian Misc. Coll., 116, No. 1 ; pp. 85. Washington, D.C. : Smithsonian Institution, 1950). He points out that in many Entomostraca, some Malacostraca and the Machilidæ, the mandible most clearly resembles this idealized coxa in structure and musculature, bearing in mind that there is no sternum as its place is occupied by the mouth. The work traces the various modifications and specializations that are to be found in all groups of mandibulate arthropods. The text is illustrated with twenty-five text-figures and the majority of these have seven or eight individual diagrams.

\section{Annual Conference of Aslib}

IN what circumstances are mechanized aids quicker or slower than human beings in selecting information from a wealth of coded material? Can the flow of work in a library be usefully compared with that in a process plant when planning layout? Would the use of intelligence and aptitude tests help in choosing a better information officer? These are typical of the questions raised at the twenty-sixth annual conference of Aslib held during October 5-8 at Ashorne Hill, the conference centre of the Iron and Steel Corporation near Leamington Spa, and attended by nearly two hundred and fifty delegates. The theme of the conference was 'design for efficiency'. The particular fields in which problems of increasing efficiency were studied were: international bibliography ; optimum use of staff and training the user ; and the future development of Aslib. The formation of subject groups within the framework of Aslib in the fields of aeronautics, food and agriculture, textiles and economics stimulated lively discussion. Some constructive co-operative plans for rationalization in the purchase, listing and loan of periodicals, for exchange of staff, and for translation have already been initiated. In the sessions on choosing, training and directing staff, and on training and directing the (unchosen) user, scientific and statistical methods of assessing the problems attracted the interest of delegates. It was noticeable that attempts to measure the capabilities of persons and the efficiency of processes are increasing. Unesco's efforts to stimulate the development of bibliographical services in underdeveloped areas and to tidy up the existing services elsewhere were described in a paper submitted by the head of the Libraries Division of Unesco. Added interest was provided in this session by contributions both from members of the Organization for European Economic Co-operation (O.E.E.C.) mission at present touring Europe to study technical information services, and also from delegates recently returned from the Conference of the Fédération Internationale de Documentation in Rome. The Conference not only provided the usual stimulus of contacts between specialists, but also raised problems that may be profitably pursued by smaller groups in the future.

\section{University of Birmingham}

THE following appointments have recently been made in the University of Birmingham: P. J. Palmer, formerly of the Boulton Paul Aircraft Co., to be lecturer in civil engineering; J. H. O. Varley, to be lecturer in metallurgy. The following resigna. tions from the University have been announced: Dr. E. S. Twyman, lecturer in botany, on appointment as professor of botany in Rhodes University, Grahamstown; W. S. Norman, lecturer in chemical engineering, on appointment as lecturer in chemical engineering in University College, London; Dr. A. J. Wilson, lecturer in mechanical engineering, on appointment to the Metals Division of Imperial Chemical Industries, Ltd. ; Dr. Mary Gregg, lecturer in botany, on appointment as lecturer in botany in University 